\title{
REVISIONES
}

\section{Hitos Significativos de la Política Educacional del Gobierno de la Coalición por el Cambio (2010-2014)*}

\author{
Significant milestones of the Educational Policy of the Government of \\ Coalition for Change (2010-2014)
}

\author{
Jorge Alarcón Leiva, ${ }^{a}$ Sebastián Donoso Díaz ${ }^{a b}$ \\ anstituto de Investigación y Desarrollo Educacional, Universidad de Talca \\ Correo electrónico: joalarcon@utalca.cl \\ bCorreo electrónico: sdonoso@utalca.cl
}

\section{RESUMEN}

El artículo caracteriza las principales iniciativas de política educacional de la alianza política que gobernó el país por cuatro años, examinando sus principales propuestas, al tiempo que se exploran interpretaciones para determinar la índole del proceso experimentado por el sector durante el primer gobierno democrático de derecha en Chile de los últimos 50 años. En este contexto, se describen dos aproximaciones evaluativas que decantan en una perspectiva final de análisis que sitúa la política educacional chilena en el contexto del debate social en su conjunto.

Palabras clave: política educacional, Coalición por el cambio, agenda política, movimientos sociales, Chile.

\section{ABSTRACT}

The article characterizes the main initiatives of educational policy of the Chilean conservative political alliance that ruled the country for four years (2010-2014), examining its main proposals, while exploring interpretations to determine the nature of the process experienced by the sector during the first conservative democratic government in Chile over the last 50 years. In this context, two evaluative approaches are detailed and compiled to give a final perspective analysis that places the Chilean educational policy in the social debate as a whole.

Key words: educational policy, Coalition for change, political agenda, social movements, Chile.

Texto constitutivo del Proyecto "Profundización abierta y encubierta del mercado: La política educacional del Gobierno de la Coalición por el Cambio (2010-2013)", Proyecto FONDECYT n ${ }^{\circ}$ 1150350, apoyado por el Fondo Nacional de Investigación Científica y Tecnológica de Chile. 


\section{PRESENTACIÓN}

Después de cincuenta años, la derecha política chilena lograría vencer democráticamente en las elecciones presidenciales de comienzos del año 2010, habiendo alcanzado su candidato, Sebastián Piñera, un 51,6\% de los votos y consiguiendo superar así a la Concertación de Partidos por la Democracia (en adelante, "Concertación”), que había gobernado el país los 20 años siguientes tras el término de la dictadura.

Entre las promesas de campaña del candidato Piñera, destacó su insistencia en constituir una alternativa para una "nueva forma de gobernar", basada en la eficiencia como símil de la empresa privada, y cuyas expectativas se expresaron sintéticamente en la célebre afirmación del $1^{\circ}$ de abril de 2010 en que sostuvo sentir que se había avanzado en sus primeros 20 días de gobierno lo que otros no lograron avanzar en 20 años, en clara alusión al sector político opositor. La "nueva forma de gobernar", además, contaba con un componente que para la coalición gobernante (en adelante "la Coalición") era parte consustancial de la retórica que había introducido, a saber, la idea-fuerza de que este, el gobierno de la Alianza, era "de excelencia".

Ocurría esto en medio de un profundo proceso de cambio experimentado a causa de las circunstancias que conducirían a la Coalición Concertacionista a dejar el Palacio de La Moneda, la sede del gobierno, prácticamente al mismo tiempo que ocurriera el terremoto de febrero de 2010 que afectara al área territorialmente más poblada del país y que impactara la vida de muchas personas cambiando, entre otras varias cosas, la infraestructura educacional del territorio afectado, puesto que del orden de 4 mil establecimientos escolares padecieron las consecuencias devastadoras del terremoto.

A consecuencia de ello, la agenda política del gobierno entrante experimentó una transformación sustancial. Si bien ello no cambió el sentido global de la política educacional en particular, sí tuvo incidencias trascendentes en el proceder del Gobierno. Adicionalmente, el año siguiente, 2011, antes de finalizar el primer semestre, se desató uno de los conflictos estudiantiles y sociales más significativos experimentados en el país desde finales de la dictadura, el cual aceleró los procesos de adhesión ciudadana en torno a la necesidad de modificar ya no solo cierto conjunto de iniciativas específicas del sector, sino de radicalizar la tendencia que conduciría a hacer evidente una transformación fundamental, en un sentido tal que dejara al país ad portas de un virtual cambio de paradigma (Donoso \& Alarcón, 2015).

Así lo ponen en evidencia las cifras de las movilizaciones:

De acuerdo a cifras oficiales, solo en la región metropolitana se autorizaron 240 marchas — versus 134 en 2010 - , lo que corresponde a un promedio de 20 marchas mensuales [...] las cifras a nivel nacional, por su parte, estiman en alrededor de 6000 manifestaciones públicas y 2000000 de participantes durante el año [...] estos son los niveles de movilización social más altos vistos desde 1990.

En el balance final del Gobierno realizado por el Instituto Libertad y Desarrollo Think Tank afín al Gobierno- se señala que:

El tema Educación fue, sin duda, el ámbito de más tensiones políticas y comunicacionales para el Gobierno. Masivas marchas el 2011 y consignas instaladas como "fin al lucro" 
o "gratuidad de la educación", incluso entre algunos de sus partidarios, desdibujaron la agenda original que se había presentado en la campaña, obligando a La Moneda a reaccionar ante el fenómeno estudiantil. (Instituto Libertad, 2014, p. 5).

Tanto la masificación de las demandas, cuanto la introducción de nuevas consignas que replicaban sinópticamente el significado y alcance de las exigencias de la ciudadanía —una retórica ciudadana que hacía frente a la retórica de la Coalición gobernante — son sintomáticas de una transformación que sobrevendría en la política educacional chilena junto con la instalación y el posterior despliegue del nuevo gobierno a partir de marzo de 2010.

En esta lógica, y atendiendo las orientaciones de Kingdom (2003) respecto de la agenda de políticas públicas como conjunto de procesos que requieren establecer alternativas específicas y decidir caminos de acción, para que den curso a su implementación, puede sostenerse que el Gobierno de la Coalición por el Cambio no logró instalar una agenda viable que ordenara y diera coherencia a su accionar, y le permitiera de esta forma liderar el derrotero del sector educativo. Por el contrario, su debilidad quedó al descubierto al presentar acciones y propuestas desestructuradas y altamente ambiciosas, pero con baja capacidad de concreción, evidenciando — en lo fundamental - un estado de desorden en materia de política educacional. Para usar las palabras del propio Kingdom (2003, p. 17), en la habitual situación de "anarquía organizada" que es un gobierno, se comenzó a imponer la impresión de que la balanza se inclinaba a favor de la anarquía.

A tenor de lo señalado, si bien las consecuencias del terremoto retrasaron el inicio de la implementación de algunas propuestas del nuevo gobierno, más grave sería para dicha implementación el impacto del movimiento estudiantil, que alteró radicalmente la agenda de políticas educacionales que el gobierno se había trazado para sus años de gestión. Incluso podría sostenerse que el movimiento social del año 2011 influyó directamente sobre la agenda del actual gobierno (2014-2018), y con bastante probabilidad del que vendrá, teniendo a la vista las dimensiones e impactos que a partir de dicho movimiento produjo en la comprensión de la educación abrazada por una buena parte de la ciudadanía y que, por lo demás, sigue presente en la discusión nacional.

El sentido del texto es sistematizar, analíticamente, el acontecer fundamental del período en estudio, señalando los hitos claves que permitan comprender la secuencia, importancia y contenido de los hechos y factores de mayor incidencia en su devenir (permanencia y cambio) en los cuatro años del gobierno de derecha en Chile. El acercamiento a la identificación de los hitos clave implica más que una revisión cronológica de los sucesos, una definición de su contenido como atributo significativo, contextualizando de esta manera los hechos. Adicionalmente, desde la visión de las políticas educacionales, los hitos pueden ser considerados bajo un orden secuencial progresivo e incremental, propuesta dominante en el análisis de los fenómenos educacionales en el caso chileno, o bien ser revisados desde la perspectiva del significado que tales hitos presentan, vistos desde la perspectiva global.

En este último sentido, abundan los estudios dedicados a recabar ejemplos acerca de las transformaciones acontecidas en las sociedades occidentales desde fines del siglo XIX. Muchos de esos trabajos comparten hipótesis y zonas de análisis: señalan que estamos en presencia de un cambio de época, aunque debaten respecto de qué significa exactamente el que así sea. Algunos de ellos atribuyen estas transformaciones a las relaciones entre el mercado y el Estado, otras indican que el devenir moderno o postmoderno halla su origen en los notables impactos de las tecnologías de la información, otros postulan que tales 
transformaciones no serían posibles a menos que hubiera tenido lugar la desarticulación simultánea de las organizaciones nacionales propias de la política moderna.

En lo que sigue se explora una hipótesis alternativa. Las razones de ello se deben al intento de conferir sentido a la sensación tan común de estar viviendo un periodo arduo, un momento histórico en que cohabitan aspiraciones rayanas en la anarquía e invocaciones al orden, un tiempo de delirios contestatarios y de raptos de disciplinamiento burocrático; una época de contradicciones que parecen no acabar y, más bien, adoptar nuevas y nuevas formas, llegándose a un estado de paroxismo difícil se explicar.

La hipótesis procede de la creencia de que algo muy profundamente nuevo está aconteciendo y está motivado por lo que Herzog, el personaje de Bellow, señala en una de sus delirantes cartas: "Pocos intelectuales han captado los principios sociales que hay detrás de esta transformación cuantitativa" (Bellow, 1964, p. 73), refiriéndose al hecho de que los habitantes del planeta alcancen una cifra superior a 2000 millones de habitantes y que esta cifra sea por sí misma "una especie de milagro" que deje "anticuadas nuestras ideas prácticas" (Bellow, 1964, p. 73). Se requiere examinar el estupor de la frase de Bellow, el mismo temple al que alude Zizek al referirse a la "forma hegemónica del multiculturalismo" con el que dice que nos inunda hoy la prensa liberal, tratando de hacer que nos olvidemos del problema real: la "despolitización de la economía" que es la "ideología del actual capitalismo global" (Zizek, 2008, p. 11).

Al mismo tiempo que nos asombramos de las cifras — demográficas, delictivas, pero sobre todo económicas - nos quedamos silentes. Las cifras parecen fragmentos de mensajes, sustraídas de su entorno humano: el punto en el que Zizek coincide con Sennet, en la medida en que ambos indican que lo que caracteriza un cierto momento de la evolución de las sociedades modernas occidentales es un estado de "afasia". Así, en tanto que para Zizek la cuestión reside en "politizar la economía" (Zizek, 2008, p. 12), mediante un gesto que la traduzca al lenguaje de la ideología, para Sennet (2007, p. 27), aludiendo a las limitaciones de la manera en que Weber se representó la sociedad, sobrevino un quiebre cuando la obediencia se transformó en interpretación (Sennet, 2007, p. 34), vale decir, cuando la sociedad construida sobre el modelo militar prusiano creció al punto de necesitar interpretar las relaciones entre los individuos.

Los fenómenos a que aluden tanto Zizek como Sennet — la despolitización de la economía, la pretensión de que en ella hay meros números y la transformación de la obediencia en interpretación del orden- son parte de la experiencia ciudadana chilena de los últimos cuarenta años. En efecto, en el cruce que describen Zizek y Sennet es donde se encuentra la política educacional chilena o el lugar en que la dejó el gobierno de derecha, en su reestreno en el gobierno nacional del país. Es este mismo cruce el que en parte explica y en parte produce los resultados alcanzados porque, a fin de cuentas, la política educacional chilena termina adoptando con mucha frecuencia el ropaje de la New Public Management o nueva gestión pública.

\section{LO QUE SE HEREDA NO SE HURTA}

La educación chilena ha estado marcada, desde mediados de la década pasada (2006), por conflictos que han buscado corregir aquellos severos desequilibrios que, teniendo su origen fuera del ámbito educativo, han impactado decisivamente a una educación pública, cuya 
profunda pauperización parece haber estado inscrita en el destino de las transformaciones originadas durante la dictadura. Tanto es así que para comprender el proceso de declive de la educación pública, es necesario remontarse a la reforma del sistema educacional del año 1980, que implicara cambios sistémicos en relación con su organización institucional, su estructura normativa y los mecanismos de su financiamiento.

Tales modificaciones respondieron, a su vez, a la transformación del rol del Estado desde una concepción de bienestar a una que lo concibe como subsidiario; una concepción desplegada por la dictadura cívico/militar desde casi los inicios mismos de su gobierno y sancionada después con la Constitución de 1980, a fin de alinear al sistema educativo con las políticas a las que venía plegándose sin excepciones la vida nacional (Rodríguez, 2005), todas las cuales derivaban de la extensión de los criterios aplicados por las administraciones de Thatcher y Reagan, como muy bien lo muestra, entre otros, Harvey (2007).

Las implicaciones de la metamorfosis del rol del Estado se manifestarían tanto en cómo se comprende y en cómo se distribuye la educación (Donoso, 2013), en un plexo de complejas relaciones, cuya descripción sería más o menos la siguiente. La estabilidad del pacto social depende de aceptar que los actores primarios son individuos, cuya acción libre ("económicamente" libre, ha de entenderse) suministra todo lo necesario para la vida social: bienes materiales —y, vamos a conceder-, también bienes simbólicos. Cuando ello no sea posible - supongamos bona fide que ello se produzca por justificadas limitaciones al emprendimiento privado, debidas a insuficientes y/o malas regulaciones-el Estado deberá proveer bienes y derechos básicos de forma directa, pero, por defecto, o subsidiándolos.

Una consecuencia de la distinción del rol del Estado respecto del rol de los privados, para el caso de la educación, será que, una vez superados los estándares mínimos que deben ser asegurados por el Estado, la educación puede pensarse perfectamente como bien de consumo, es decir, no como un bien público cuyo aporte fundamental es su valor público. En este contexto, los gobiernos de la Concentración (1990-2010) son divisibles desde la política educacional en al menos dos grandes ciclos políticos.

El primero, correspondiente al período 1990-1999, puede considerarse de correcciones al modelo de mercado y de intento por reposicionar la educación pública, sin alterar las reglas imperantes (de mercado) en materias de financiamiento y organización del sistema educacional. La segunda fase, de los años 2000 a 2009, es de administración del modelo y de masificación de la educación terciaria, denunciándose entonces fisuras importantes entre las propuestas del modelo y los resultados registrados. En este marco hay que señalar el movimiento estudiantil del año 2006 como un predecesor y detonante importante de los cambios que posteriormente enfatizaría el movimiento del 2011.

Entre los temas no resueltos por la administración de Bachelet durante su primer mandato, y que permanecerían pendientes, estaban básicamente los referidos a educación superior en sus diversos ámbitos: cambio de las reglas del juego del sector, sistema de financiamiento, procesos de admisión y otros que posteriormente, en el movimiento del año 2011, resurgieron, entre los que destacan sin duda el tema del lucro de las instituciones educativas, la gratuidad de la enseñanza, etc. En una medida importante, se quiere señalar que, dada la semejanza estructural mediante la cual es Estado se relacionaría con la provisión de bienes necesarios para cubrir derechos como los de la educación, cuando los temas no constituían parte del horizonte inmediato de los intereses ciudadanos, la definición de la agenda en educación seguía manteniéndose en los márgenes pre-definidos por la Dictadura en su Constitución Política del año 1980, pese a sus modificaciones siguientes. 
También en materia del sistema escolar había demandas importantes en muchos ámbitos, una de ellas se refería al fortalecimiento de la educación pública, no solamente al de la gestión del sector, sino a su impacto, atendiendo entonces cuestiones cruciales de organización y financiamiento. También se extendía a demandas de cambio de la formación de profesores, considerando las normas que rigen la carrera docente (estatuto docente). Estas cuestiones, como las antes dichas acerca de Educación Superior, se mantendrían dormidas mientras no se incluyeran —-mucho antes de ser puestas en la agenda políticaentre los asuntos que nutrían las consignas reivindicatorias de los movimientos sociales.

Adicionalmente, entre una serie de otras cuestiones no resueltas, se requería definir con mayor especificidad las institucionalidad que había sido establecida en la Ley General de Educación (2009), discutida y aprobada en el período final de la Concertación, que implicaba instalar una macro estructura de funcionamiento que por una parte debilitaba aún más la alicaída labor del Ministerio de Educación y, por otra, elevaba el rol regulador del aparato público — cuestión propia del modelo neoliberal ${ }^{1}$ — con la creación de la Superintendencia de Educación Escolar y la Agencia de Calidad de la Educación, esta última preocupada de la medición de resultados básicamente de aprendizaje del sistema escolar.

Sin lugar a dudas, la principal herencia latente que legaría la Concertación en sus veinte años de gobierno fue el no haber modificado sustantivamente, sino que más bien el haber validado, el paradigma neoliberal que concibe a la educación como un mercado (o un cuasimercado), en el marco del cual las familias tienen el derecho de elegir el establecimiento donde educar a sus hijos y en donde el Estado cumple fundamentalmente un papel regulador y subsidiario. Las implicancias de esta herencia son múltiples y suponen una determinada comprensión del rol de la educación pública, la definición de la educación como un bien privado o semipúblico, así como a las diversas consecuencias de ellos para entender a los actores que demandan y a los que proveen educación.

Esta estructura, como ha sido dicho, se mantendría intacta y constituirá una suerte de non plus ultra con el cual la clase política chilena mantendrá relaciones ambivalentes y con la que, a su vez, la ciudadanía se confrontará en repetidas oportunidades, no sin ser a veces dominada por ella. Se trata, en efecto, de un muro ideológico construido durante los años de la dictadura, que tendió a naturalizarse con el paso de los años al punto de ser, en nuestra opinión, un componente fundamental de lo que Whitty (2000) llamara "privatización ideológica”. Dicha privatización tiende, como buena ideología que es, a hacernos pensar que más allá de esta forma de organizar la vida social no hay otra razonable; que una alternativa de vida social no es aconsejable; que, de hecho, un más allá no es siquiera concebible, con lo cual se produce el efecto de convertir a esta manera de pensar en sentido común.

Pues bien, parte de la cuestión planteada por la política educacional del gobierno de la Coalición por el Cambio depende de entender cómo las iniciativas adoptadas durante su periodo de gobierno se alinearon con dicho sentido común y cuánto de ese sentido común pudo ser modificado por la irrupción de acontecimientos que caracterizó su mandato. En esta lógica, bien puede decirse que el análisis del gobierno en cuestión exige atender a la lógica que hizo posible que concluyera con un nivel extraordinario de aversión en la opinión pública. El que esto haya sido posible prueba que el sentido común de la política chilena está sujeto a reglas de construcción bastante distintas de las que habitualmente se

El neoliberalismo sostiene que los problemas se han producido por fallas regulatorias, pero la evidencia muestra que nuevas regulaciones no implican un mejor mercado, ello aparece extensamente tratado en Krugman (2009). 
usan para explicar la formación de creencias, y que la preservación y cambio de las ideas que constituyen el sentido común obedecen a reglas también diferentes de las que usamos para entender el cambio de creencias (Lakoff, 2004).

\section{LA NUEVA MANERA DE GOBERNAR: LA NARRATIVA DE LA CALIDAD}

Hacia el final del gobierno de la Coalición, en parte fruto de sus perceptibles limitaciones prácticas para hacer frente a los desafíos que halló una vez asumido, o que se autoimpuso como resultado de la contienda electoral, fueron varios los intentos de los protagonistas del ejecutivo por defender el valor y el alcance de las iniciativas de política adoptadas en distintos ámbitos. Entre ellos, el educacional.

El impulso por mejorar la evaluación de la ciudadanía respecto del desempeño del gobierno procedía de los momentos finales del gobierno, contexto en el cual la situación hacía evidente la deficiente evaluación pública que existía, lo que comprometía la posibilidad de extender la primacía de la derecha en el poder, de una parte, y el que a mediano y largo plazo quedara en la conciencia colectiva la idea de un fracaso político que hipotecaría toda posibilidad de una eventual reelección del propio Presidente Piñera. En suma, se trataba de un estado de cosas sorprendente, toda vez que correspondía al final de un gobierno que había declarado su intención en orden a llevar a cabo una nueva forma de gobernar, cifrada por el ideario de la eficiencia y de la excelencia.

En esta lógica, se pretendió establecer una agenda políticamente prometedora, capaz de afrontar la baja en las encuestas: se aumentó la subvención, se reforzó la labor de selección y formación de directivos escolares, se aumentó la cobertura para la primera infancia, se implementaron convenios de desempeño para universidades que enseñaran pedagogía y, mucho más contingente pero también más sintomáticamente e, incluso, buscando deponer la movilización estudiantil, se rebajó considerablemente los intereses para gestionar créditos universitarios con aval del Estado. Todo ello haciendo las correcciones debidas en las medidas para evitar dar un paso en falso y, desde luego, acompañado de una retórica grandilocuente, orientada a incubar la idea de que se estaba frente a enormes e históricos cambios, cuando lo que en realidad estaba pasando era, esencialmente, la implementación de un conjunto relativamente inconexo de acciones.

De modo que, por cierto, se pueden enumerar las iniciativas, pero esto pudiera carecer de sentido, a no ser que, dado el contexto en que se tomaron, se examine el encuadre o la narrativa sobre cuya base se pretendió atribuirles valor o dar sentido. En especial, en aquellos aspectos fundamentales de la "doctrina neoliberal", sus dogmas, por ejemplo en cuanto a la particular significación de la libertad individual y su relación con la así llamada "libertad de enseñanza".

En este último punto, la derecha había logrado imponer por largos años la interpretación conforme a la cual la expresión "libertad individual" adoptaba en educación una significación especial para interpretar la "libertad de enseñanza", la que consecuentemente obligaba a entender a la última como "libertad de iniciativa", es decir, como extensión "natural" de la libertad de los individuos por llevar adelante emprendimientos de naturaleza económica que contribuyeran a la labor educativa de los padres y a la labor "subsidiaria" a que estaba obligado el Estado en esta materia (Constitución Política, Art. 19 10-11). Pues bien, se necesitaba sostener esta regla hermenéutica sin comprometer la popularidad política, sobre 
la base de una lógica que introdujera esta vez la necesidad de diferenciar educación pública y educación privada, es decir, pagada, mediante un contenido que resultara políticamente persuasivo: en esto jugaría un rol decisivo el uso de la palabra "calidad". La "calidad" habría de convertirse así en el nuevo caballo de batalla, en la clave de la privatización encubierta del sistema educativo ${ }^{2}$, capaz de neutralizar los afanes por imponer intereses ideológicos -y cualquier interés es ideológico, puesto que lo único librado de todo interés es la calidad-que desviaran la atención respecto de lo realmente importante: la calidad de la educación. Lo demás, todo lo demás, es como se dice: literatura.

Por ejemplo, en la pulcra y muy estudiada narrativa de la calidad se sustentó en 2010 la iniciativa de los "mapas de resultados SIMCE", que adquirió la tan publicitada como criticada forma de los semáforos, cuyos colores, bajo el imperativo de dar una mayor y más legible información a los padres, se distribuyeron en el mapa real de los establecimientos a fin de indicar que los rojos describían zonas de "mala calidad", los verdes "zonas de buena calidad" y los amarillos "zonas de calidad intermedia". La pulcritud de la esta narrativa de la calidad debe interpretarse como la resultante de una nueva manera de hacer política: los colores describen, no califican, zonas del territorio educativo, por mucho que en ellas se "señalizara" a los establecimientos escolares en que se desempeñan docentes "malos", "intermedios" o "buenos" y, consecuentemente, se indicara que había zonas menos elegibles que otras. Como era el caso, de hecho, pero sin que con esto se pretendiera más que señalarlo. La defensa de la medida se basaba, de esta forma, en que describir cómo son las cosas es parte de cómo son las cosas, es decir, no obedece a ningún otro propósito que el de dar cuenta de las cosas mismas ${ }^{3}$. Esta iniciativa tuvo corta vida, esencialmente por lo inútil de su propuesta y la baja, si no negativa, aceptación que tuvo en la ciudadanía.

Por otra parte, la designación de un conjunto de 60 liceos a lo largo del país como instituciones o establecimientos Bicentenario, constituyó otra medida importante para el gobierno. Los liceos se ubican en distintas regiones del país y responden al objetivo de entregar educación de alta calidad a estudiantes vulnerables. Con ese fin, aplican rigurosos mecanismos de selección académica mediante pruebas estandarizadas de conocimientos y competencias, principalmente en las áreas de Lenguaje y Matemáticas.

Su existencia, por tanto, se justifica en virtud de ofrecer "educación de alta calidad", por lo que forma parte de las iniciativas sustentadas en la narrativa que buscó ofrecer una manera de suprimir el discurso diferenciador entre tipos de establecimientos por constituir esta una variante ideológica de "lucha de clases". En efecto, los liceos Bicentenario - la metáfora nacionalista de la conmemoración de 200 años de independencia nacional, juega un importante rol en la nueva retórica - suprime la diferencia entre público y privado, en pos de subrayar que lo importante, lo verdaderamente importante, es la calidad. Sin importar su origen, su destino: sin historia. De esta manera, la argumentación de la nueva forma de gobernar subrayaba que el suyo no era, en rigor, discurso, nada de palabras; al mismo tiempo, que se trataba de las cosas como eran, nada de interpretación. Esta iniciativa estuvo igualmente desligada de otras propuesta de política, si bien permanecen como tal los establecimientos escolares de este tipo, que se suman a algunos liceos públicos emblemáticos, denominación atribuida a su historia y resultados, en la práctica

\footnotetext{
La privatización encubierta es una fase posterior a la "abierta" siguiendo los planteamiento de Ball y Youdell (2007).

Los Mapas escolares reflejaron la fuerte asociación entre la situación socioeconómico del territorio y los resultados escolares. Adicionalmente este instrumento no medía avances o retrocesos, sino situaciones estáticas.
} 
segmentaron más el mismo sector de la educación pública con establecimientos de primera y segunda categoría (buscando que los primeros se asemejen a los privados). El tema de fondo, no resuelto a la fecha, es que el mismo Estado respeta y transgrede sus propias normas (Tomasevski, 2004) y, más aún, estos establecimientos de primera categoría atienden a la población menos pobre, es decir el mismo Estado termina discriminando a los pobres, pues estas oportunidades educativas se asocian a selección abierta o encubierta de estudiantes, como se ha venido planteando desde el año 2004 y posteriormente denunciado por el movimiento estudiantil del año 2006.

Durante 2011 tuvo lugar, por último, el movimiento de los estudiantes universitarios, un movimiento marcado por el fuerte liderazgo de los presidentes de las federaciones de las, a su vez, más fuertes instituciones de educación superior del país: las universidades de Chile y Católica de Chile. Este movimiento instalaría un verdadero cisma ya no solo con el Gobierno de la derecha, sino con el conjunto de la así llamada "clase política", incluyendo a la oposición. Sería, entre otras cosas, el detonante que permitió establecer una línea ideológicamente continua entre los gobiernos de la Concertación y el de la Alianza. Pese a la fuerza del movimiento de estudiantes, prontamente transformado en llave maestra de la gobernanza, ninguna autoridad ministerial saliente pudo construir una relación productiva con el movimiento estudiantil, siendo incluso motejado por algún personero: "inútiles subversivos". El calificativo no es trivial: los estudiantes debían ser controlados y la mejor forma de hacerlo consistía en inscribirlos en la narración que el país trataba de dejar atrás, aquella del desorden y de la inutilidad, por oposición al orden y la utilidad.

De hecho, es evidente que lo que más se recordará en el periodo de la Coalición gobernante no serán ni las reformas ni las leyes o medidas impulsadas. Lo que quedará en la retina pública serán los argumentos que construyó el movimiento social por la educación, precisamente el movimiento que el gobierno de derecha pretendiera demonizar, argumentos destinados a reponerle a la educación el carácter de un derecho social (Atria, 2014). Esto es lo que hizo desde entonces necesario abordar un antiguo pendiente: la vinculación del Estado y de la Educación Pública (Bellei, 2015).

Con posterioridad a la primera parte del gobierno, bajo el control del gabinete de educación por parte del Ministro Lavín y su consecuente salida debida a la fuerza del movimiento de estudiantes universitarios, y a la acusación constitucional interpuesta en el Congreso por la oposición, asume el Ministro Bulnes quien en un documento de agosto de 2011, "Políticas y propuestas de acción para el desarrollo de la educación chilena", establece el derrotero de su trabajo que será, en una medida importante, un mapa de los hechos futuros.

En general, el documento constituye un avance sustancial a lo propuesto y realizado por el ex ministro Joaquín Lavín, en la medida que integra propuestas para todos los niveles educativos (preescolar, escolar y superior), acoge algunas ideas y propuestas de actores sociales, tales como el reconocimiento constitucional al derecho a una educación de calidad y el deber del Estado de velar por ella. Además, en el ámbito escolar, se abre a modificar el sistema municipal de educación pública; a incluir fuentes de financiamiento estatal sobre la base de la matrícula y no solo de la asistencia; a regular en forma más decidida los ingresos, gastos e inversiones de los establecimientos educacionales públicos y privadosubvencionados; y a fortalecer la educación secundaria técnico profesional, entre otros.

Si bien las ideas propuestas a nivel escolar se hacen cargo de resolver problemáticas claves del sistema educativo actual, el documento no clarifica cómo se abordarán aspectos 
fundamentales tales como el fortalecimiento de la educación escolar pública, que venía presenciando una marcada baja de su matrícula. Diversas razones y motivos explican esta baja en la matrícula escolar pública. Factores tales como la facilidad para la apertura de colegios privado-subvencionados, su escasa regulación y control, la falta de un límite al número de establecimientos privados que se pueden abrir por comuna, el atractivo que este tipo de colegios significa para las familias por su nueva infraestructura y equipamiento, la falta de un plan de fortalecimiento del sistema público que confiera competitividad al sistema público frente al privado, entre otros, explican la tendencia.

En resumen, el documento del gobierno muestra avances importantes, comparándolo al limitado proyecto GANE ${ }^{4}$ presentado por el Ex Ministro de Educación Joaquín Lavín y el propio Presidente Sebastián Piñera, y se abre a discutir aspectos clave como la desmunicipalización y la regulación del lucro. El problema es que los principios orientadores esbozados son los mismos que han inspirado a la derecha desde los ochenta. En otras palabras, la inclusión del Ministro Bulnes constituyó un acierto, pero no dejaría de seguir "gobernado" por las limitaciones de una concepción de los bienes educacionales que, como se dijo, fue construida lenta y sólidamente a partir de la Dictadura. Con todo, el manejo que de sus principios hiciera el Ministro Bulnes presentó la virtud de haberse conducido siempre con prudencia política, una forma de hacer las cosas que hizo posible que bajo el mandato suyo en el sector educacional no se presentaran otros episodios críticos, como los que experimentara su antecesor en el cargo.

\section{LA NUEVA FORMA DE GOBERNAR: LA GERENCIA PÚBLICA}

La preservación de los principios básicos de organización del sistema educacional es un problema, porque en el caso chileno el modelo de desarrollo neoliberal ha sido incapaz de dar cuenta de dificultades tales como la excesiva segregación social y económica que existe entre escuelas públicas y privadas en el país, la falta de integración social del sistema educativo, las desigualdades de aprendizaje que se derivan de esta segregación, las trabas al financiamiento de la educación pública-municipal, especialmente en los sectores de mayor vulnerabilidad social, la escasa regulación de que son objeto los colegios privadosubvencionados, la falta de espacios para la colaboración entre escuelas públicas y privadosubvencionadas, entre otros (Donoso, Castro \& Alarcón, 2015).

En este marco, la característica del gobierno de derecha para educación parece haber consistido en la ausencia de un proyecto político enmarcado en un horizonte de mediano y largo alcance. Es decir, no hubo un proyecto político en educación, se careció de relato más allá del mercado. Este rasgo puede corroborarse en el uso de la noción de calidad como parte de una narrativa: se trató, según se ha señalado, de un relato sin historia, sin discurso, o bien prendidamente sin discurso, en cuanto suponía asumir que la calidad era un atavío de los hechos, no de la evaluación.

Si bien es cierto que los períodos de gobierno de cuatro años favorecen las propuestas de corto plazo, en la gestión en comento, el corto alcance fue una cuestión de principio,

El Gran Acuerdo Nacional por Educación, fue una iniciativa de política que no tuvo ningún impacto ni trascendencia, debiendo prontamente ser reemplazada, debido el tenor de las protestas de los movimientos sociales, reforzada por el cambio del Ministro Lavín y su reemplazo por el Ministro Bulnes. 
una decisión, no mera falta de previsión ni negligencia. Su primer "Ministro-gerente" en educación, Joaquín Lavín, fiel a su estilo — de usar figuras "cosistas" buscar convencer con medidas efectistas-, introdujo la implementación de los Semáforos Escolares como una forma de hacer públicos los resultados de SIMCE. La utilización de este efecto, el color, el semáforo, la incitación a avanzar del verde, a detenerse del rojo, etc., son palmaria expresión del intento por mimetizar la vida cotidiana con la política, traduciendo las sofisticadas razones de expertos a simples bites de evidencia.

Se sumó a esto la creación de varias comisiones de expertos en distintas materias educacionales, cuyos resultados no fueron revisados más allá de algunas aulas universitarias $\mathrm{y}$, por cierto, no se constituyeron en referentes de las políticas implementadas por la administración ${ }^{6}$. Actuaciones gubernamentales que sometieron a estudio, por más tiempo del debido, el uso del presupuesto del Ministerio de Educación, la creciente disminución de su volumen de personal — su jibarización—, la creación de instancias administrativas paralelas que capturan personal y financiamiento, Superintendencia de Educación Escolar y Agencia de Calidad. La discontinuidad de algunos programas del Ministerio, desafección de un número importante de sus funcionarios instalan en su impronta dos cuestiones estrechamente asociadas que constituyen su racional de operación en todo el período, a saber: fortalecer el desarrollo del mercado en educación, cuya meta será aumentar al máximo su grado de privatización (abierta y encubierta); y, segundo, demostrar, midiendo todo lo que se pueda medir, que la educación privada de cualquier laya es mejor que la pública, para sustentar el paradigma privatizador.

Apenas estrenado el segundo año de gobierno, el poderoso movimiento estudiantil del año 2011, dejó fuertemente herido su débil proyecto educacional inicial y también los siguientes: el Gran Acuerdo Nacional por la Educación (GANE) tiene una vida efímera, y la Reforma Tributaria pro-educación no lograría recaudar — según los expertos- los recursos esperados y menos los requeridos para implementar la que en palabras del Presidente Piñera era "la mejor y más grande reforma educativa del país"; reforma de la que después — si acaso — se hablaría solo para murmurar una respuesta a la pregunta sobre por qué razón no se habló más de ella ${ }^{7}$. Son los días de exaltación del marketing y de la incontenible necesidad de creer y hacer creer que se hacía historia, formulando anuncios grandilocuentes que al poco andar mostrarían su falta de consistencia.

El movimiento de estudiantes universitarios y secundarios se transformó, contra todo pronóstico del gobierno y cierta sorpresa de la oposición, en una corriente social incontenible, básicamente porque desnudó la desnutrida política educacional y también parte de la anodina política Concertacionista en educación, instalando desde ese momento en la agenda país los temas que han sido y son el eje de las actuales problemáticas en el sector. Así, la educación es el centro de la agenda del segundo gobierno encabezado por Bachelet, con sus demandas de educación pública gratuita y de calidad, asociada al fin del lucro en educación.

"Cosista" se emplea como sinónimo de alguien que se preocupa de detalles y de aspectos prácticos menores, pero sin mayor trasfondo.

6 Se crearon al menos dos comisiones de expertos en educación, cuyos informes no son referentes relevantes sobre la materia.

7 Este pareciera ser el destino de muchas reformas en nuestro medio, no en vano la misma "Reforma en Marcha", impulsada por los gobiernos de la Concertación, tiene una muerte silenciosa desde el año 2007, omitiéndose del discurso público su existencia. 
La salida del ministro-gerente Lavín, producto del conflicto estudiantil, acontece no solamente por déficit de su manejo político, por las presiones sociales de estudiantes, por los rectores de universidades tradicionales, sino esencialmente por las exigencias de los rectores de las instituciones privadas y sus dueños, que temían el escalamiento del problema del lucro, ante el reconocimiento del ministro Lavín de haberse enriquecido mediante su participación en la propiedad de una universidad privada. Es decir, la razón que lo derriba es esencialmente política y deriva de su intento de haber declarado "con honestidad" que había conseguido parte de su riqueza al ser parte del lucrativo negocio educativo.

El Ministro Bulnes buscaría encauzar el conflicto sin el éxito esperado. Los temas de la agenda del movimiento estudiantil estaban ya instalados, anclados en el escenario político nacional, abarcando un campo mayor al inicial porque también afectaban significativamente la evaluación de los gobiernos de la Concertación, al menos desde el 2000 en adelante, extendiéndose la discusión a tres materias: el cambio constitucional para fortalecer al Estado y la educación pública; fin al lucro en educación; fortalecimiento de la educación pública en todos sus niveles. Estos temas permitieron una evaluación retroactiva del quehacer político de la Concertación y facilitaron proyectar el desarrollo de la política chilena con posterioridad al gobierno de la derecha, hasta el presente año 2016 cuando menos.

Un dato llamativo, a saber, el largo conflicto social del año 2011, dejó un costo importante en pérdida de matrícula escolar para el sector público ${ }^{8}$. No obstante, la sociedad en forma masiva reclamó con fuerza a favor de la gratuidad de la enseñanza y el fortalecimiento de la educación pública, incluyendo la educación superior. Esta situación es toda una paradoja y señala en la dirección indicada antes, cuando se mencionaba la necesidad de evaluar la manera de generarse el cambio de la opinión pública. Esta es una opinión constituida por un sistema de creencias cuya estructura y eventual mutación está lejos de ser adecuadamente comprendida por alguna clase particular de "ciencia".

Mención aparte merece la actuación de la Subsecretaría de educación. Durante el gobierno bajo análisis (4 años), hubo cuatro ministros de educación (Lavín, Bulnes, Beyer y Schmidt) y un solo subsecretario. Esto debiera ser considerado como una señal de la relevancia concedida u obtenida por este actor. De forma que mientras se producían continuos acomodos en el segmento más visible del Ministerio, en el segmento interno no había cambio ni de persona ni de orientación. En efecto, por más altas que fueran las olas en la superficie — podría decirse - el subsecretario permanecía tranquilo en el fondo. Tranquilo, pero haciendo su tarea, una tarea que era, por cierto, netamente política de proporciones, a saber, fortalecer y acelerar la privatización, ahora encubierta de la educación pública ${ }^{9}$.

La subsecretaría marcó la pauta gubernamental. De sus filas salieron los directivos de la Superintendencia y Agencia de Calidad, bajo su coordinación se generaron los cambios que debilitaron los marcos curriculares y las normas que con posterioridad se encargaría de fiscalizar la superintendencia escolar. Bajo su dirección se produjo la instalación de la nueva institucionalidad del sector, y desde su influencia se buscó asociar aún más a los sectores medios con la educación privada, siendo quizás su iniciativa estrella, que no pudo ser

Del orden de un $3 \%$ en forma directa, traslado de estudiantes durante el conflicto y otro tanto al finalizar el año. Calculado sobre al base de los datos de matrícula del Ministerio de Educación de Chile, 2011 y 2012.

9 Se alude a la privatización encubierta como tarea esencial, pues ya se había privatizado todo lo fácilmente privatizable, ahora había que fortalecer la privatización ideológica, tarea que requiere de cuadros políticos disciplinados. 
aplicada, un subsidio escolar para los establecimientos que atendían estudiantes de sectores sociales medios, sin mediar ningún compromiso adicional de parte del establecimiento, idea que finalmente no prosperó, no obstante ya había sido acordado un subsidio indirecto vía descuentos tributarios anuales a los padres, por una fracción de recursos familiares destinados a educación, aunque el establecimiento fuese privado.

En suma, la navegación progresiva y a todo evento de la Subsecretaría como unidad matriz debe ser tenida bastante más que como una mera circunstancia asociada secundariamente al gobierno de derecha: se trata de una constante que operó por debajo de la aparente anarquía. El subsecretario fue el hombre del orden privatizador y, fiel a su impronta, el Gobierno de Piñera, por acción del Subsecretario, se mantuvo en concordancia con sus principios: hoy tenemos un sistema educativo mucho más privatizado que antes (matrícula) y fortalecido por los subsidios, esencialmente para los privados (pues su asignación se centra en matrícula), y con excesos de medición en muchas áreas del aprendizaje, cuya operación es privada, aunque supervisada por el Ministerio del ramo.

El Ministerio de Educación se ha debilitado con la nueva arquitectura, siendo la Superintendencia Escolar el ente determinante, bajo la idea de fortalecer el control y el castigo (cierre de establecimientos y pérdida de la condición de Sostenedor), más que la provisión de normas y orientaciones que mejoren el quehacer de las escuelas. De igual forma, la Agencia de Calidad se preocupó de ampliar las pruebas regulares del sistema (SIMCE) para muchos subsectores y niveles. No se niega el aporte de la medición, pero estos procesos masivos y repetitivos poco aportan a lo que se sabe, menos contribuyen si están desprovistos de estrategias de mejoramiento oportunas, pertinentes y con escaso soporte financiero y técnico para su implementación. Pensar que por esta vía se mejorará la calidad de la educación es, cuando menos, un "reduccionismo" que un sistema educativo no puede sostener como su estrategia sólida de desarrollo y consolidación de mediano y largo plazo.

Como el gobierno no podía traicionar su credo dogmático por el mercado, dejó en sus invisibles manos la importante tarea de coordinar las iniciativas de política. Muestra relevante de lo señalado fue el programa de Becas de Pedagogía (Vocación de profesor), que ha operado desligado de todo proceso de selección e inducción de sus graduados, es decir, sus egresados, no tienen una instancia de vínculo formal, que no sea el mercado, que permita optimizar la inversión que hace el país. Similarmente, el programa de directores de excelencia no está vinculado operacionalmente a la concursabilidad de los cargos, de manera que no representa un plus efectivo el que una persona posea esta distinción ${ }^{10}$.

El mercado que debería operar eficientemente en estos casos, no lo hace. Y así, como estos ejemplos, suman y siguen otros que muestran la incapacidad ideológica para pensar de otra manera y generar políticas efectivas y vinculadas de formación, selección, inducción, desarrollo y perfeccionamiento docente y directivo.

Finalmente, en la dimensión micropolítica se produjo el debilitamiento de la educación preescolar, contrario sensu al discurso que apunta a mejorarla. En efecto, no solamente está en elaboración un nuevo marco curricular que la debilita, sino que se adoptaron medidas que permiten a los sostenedores reducir el personal de asistentes de educación parvularia en aula, es decir, hoy los niños en el salón de trabajo están expuestos a riesgos mayores, producto de una política que apunta a reducir costos $\mathrm{y}$, por ende, incrementar ganancias

10 Selección vía Alta Dirección Pública, conforme la Ley de Aseguramiento de la Calidad ( N 20501). 
y no a mejorar la calidad de la enseñanza y su cobertura (Alarcón et al., 2016). Es decir, el fortalecimiento de este nivel de enseñanza establecido en los discursos oficiales no se condice con las medidas que se han implementado.

Un segundo ejemplo son los programas de Magíster para formar Directores de Excelencia. Atendiendo a que muchas de estas iniciativas no estaban acreditadas en el sistema nacional, sus planes primero no podían superar los tres semestres (se entiende que son de dedicación parcial y no de dedicación completa), siendo más adelante reducidos a dos semestres. Es decir, se puede conseguir un grado académico en dos semestres de dedicación parcial, algo difícil de sostener con altos estándares de calidad. Lo que implica que la micropolítica borra de un plumazo las propuestas macropolíticas tan profusamente difundidas; hemos de preguntarnos ¿por qué en educación se permiten con tanta facilidad las inconsistencias entre los diversos niveles de las políticas educacionales?

En suma, la nueva manera de gobernar se expresa en esta línea en una dimensión sorprendentemente contradictoria, presente ya en su orientación general: se trata de un gobierno que entiende la gestión pública como gestión privada, y que actuando en función de la declaración de eficiencia y excelencia, gobiernan las instituciones públicas con esos criterios. Cuando la excelencia y la eficiencia fallan, la forma de evadir la acusación de incumplimiento consiste en apelar a otra noción cara al objetivo del gerente: la calidad. Una segunda dimensión de su contradicción reside en que no resulta creíble ni menos sustentable, desde toda perspectiva que quienes no crean en lo público, a saber el neoliberalismo y su expresión política en la derecha chilena, busquen fortalecer la educación pública con iniciativas sólidas en esta dirección. Tampoco las medidas impulsadas se alinean con las propuesta de Gerencia Pública aplicadas en los años 90 (Osborne \& Gaebler, 1993), que siendo de origen privado tenían la intención neta de actualiza el proceder público para su efectivo fortalecimiento. En todos los casos, como se ve, se trata de neutralizar la ideología, que es cualquier cosa que no sea propia del discurso del gerente. El gerente despolitiza las medidas e introduce orden en el caos. Al hacerlo, convierte a la política en ciencia de la acción eficiente, tratando de convencer que ello va más allá de cualquier idolología.

\section{CONCLUSIONES}

A fines de los años 70, Lyotard (1989) se preguntaba ¿Quién decide lo que hay que saber? ¿Quién sabe lo que hay que decidir?, planteándose también la cuestión central de la política educativa nacional: mientras que en el primer caso señalaba a la legitimidad política, en el otro planteaba la cuestión del estatus del saber. Decidir y saber se han entrecruzado a tal punto en el Chile de la postdictadura que resulta difícil establecer quién ha servido a quién, es decir, si el sistema educacional ha funcionado como una réplica microscópica del sistema social o si el sistema social ha sido el reflejo macroscópico del sistema educacional. Es por ello que una parte importante de la ciudadanía considera hoy que entre ambas —entre la micro y la macropolítica - no hay más que continuidad, una continuidad pactada por los dos bloques opositores que, en la práctica, comparten los principales trozos del poder.

En parte, ello se expresa en la complejas relaciones que mantiene la educación con el desarrollo y con los derechos humanos (Tomasevsky, 2004) y en el reconocimiento de la triple dimensión del desarrollo a la que la educación contribuye, a saber, a generar condiciones de equidad, elevar la productividad y mejorar las bases de la experiencia de 
ciudadanía. Estos efectos de una "buena" educación han sido lastimosamente reducidos a su dimensión puramente económica, bajo la forma de capital humano, limitando así el amplio valor público de la educación en el florecimiento humano porque, precisamente, la educación dejó de ser mobiliario de la política y es hoy parte de la infraestructura de la economía.

En efecto, en tanto se ha pensado que la educación es una palanca del desarrollo económico, tiende a diluirse la exigencia que deriva de la condición del derecho a la educación. Por el contrario, cuando la educación se defiende como un derecho, tiende a perder valor la idea de que esta sea una parte de la maquinaria del desarrollo económico. En Chile esta tensión es la que ha estado a la base de la discusión educacional. Es la tensión que ha originado las mayores dificultades para el proceso político, por cuanto suscita la pregunta acerca de ¿Qué propósito tiene la educación? ¿A quién le corresponde su provisión? ¿Cuál es la fuente de su financiamiento? ¿Cuán selectivo debe ser el sistema educacional?

La transición a la democracia, por otra parte, ha sido un fenómeno a veces resueltamente equilibrado a veces en franco desequilibrio. Durante largos años en Chile la educación sería comprendida como un bien de apropiación privada, un bien cuyo acceso reporta beneficios individuales o privados. Bajo esta premisa se justificó, sin límite alguno, la idea de que su costo, el costo de educarse, debía ser asumido por quienes habrían de beneficiarse de la inversión, vale decir, los propios estudiantes y sus familias. La preeminencia de esta idea produjo la retirada del Estado, de cuya presencia los ciudadanos debían defenderse por tratarse de una entidad que amenazaba la autonomía y la libertad de las personas para elegir. Un Estado que no aseguraba ni acceso ni cobertura educativa y que se ha visto limitado a velar, certificar o acreditar calidad, oscilando entre la figura del Estado "remero" a la del Estado "timón”.

Crecientemente, no obstante, se adoptaría la concepción de la educación como un derecho, o más correctamente, paulatinamente hay más personas que piensan que la educación es un derecho y esta creencia emergería como una verdadera revelación, articulando una comprensión crítica de la sociedad en su conjunto. Para ser justos, esa comprensión recayó por mucho tiempo en los hombros de quienes aparecían como los herederos de la dictadura, sus representantes políticos e ideológicos, y se tardaría mucho en alcanzar la consciencia de que la privatización educacional se hallaba imbricada con algunas de las formas más ingenuas de aspiración social, el deseo de los padres por dar a sus hijos la mejor educación posible resultaría ser el dispositivo sobre el que se montó la arquitectura económica del sistema educacional: libertad de elección del establecimiento escolar para sus hijos (new deal, educational choice).

El sistema educacional chileno transformó la justificada y razonable aspiración de los padres en una máquina "mentirosa" de igualdad social con efectos nocivos sobre la formación de la ciudadanía. En cualquier caso, la sociedad chilena, o al menos una buena parte de ella, tardaría demasiado tiempo en alcanzar consciencia del efecto socialmente devastador de las decisiones que estaban efectuándose en el terreno de la política educacional en orden a someter el funcionamiento de la educación al régimen del mercado. $\mathrm{O}$, dicho inversamente, hasta hoy mismo el régimen de lo público requiere introducir un tour de force en el sistema de reglas para recién asomar.

En parte, la limitación de la perspectiva sobre la educación se debía precisamente a la creencia de estar a cubierto del caos por el consenso. El consenso fue entendido así como 
en antídoto contra la amenaza del caos. Por la idea de que el consenso operaba como el paraguas que resguardaba a nuestras instituciones y a nuestras vidas del "peso de la noche", como apuntara Diego Portales ${ }^{11}$, aludiendo al rol protector de las instituciones republicanas de las que él fuera el principal gestor. El consenso cubría las grietas de la institucionalidad política allí donde dicha institucionalidad no bastaba para cerrar del todo las múltiples fisuras de un pacto en el cual se había logrado enquistar la desigualdad y para el cual, de hecho, la desigualdad era una condición de posibilidad. Esto era, ni más ni menos, lo que el consenso político se hallaba encubriendo. Se trataba de un simulacro mediante cuyo artilugio concedía con una mano lo que la otra negaba.

Poner bajo control la situación consistió en la atribución básica de la transición democrática, una situación histórica que revelaba bien de dónde se había partido, pero cuyo destino era, con suerte, desconocido. En verdad, sin embargo, se trató del relato de un extravío democrático que sirvió como la abreviatura de un trazado que en cuarenta años llevaría a Chile de la Dictadura a la postpolítica, sin solución de continuidad.

La transición chilena constituye, efectivamente, el rápido paso de una política dictatorial a una desmovilización de la sociedad, que alcanza su punto de máxima expresión en una convivencia social bajo los imperativos de la postpolítica y que vive su máxima extensión durante la transición, un proyecto político de difusos límites temporales. La transición no fue en sí misma un momento democrático, en parte importante porque su dinámica interna exigía que no fuera siquiera un momento.

Así como se llamó a la Dictadura "paréntesis en la vida republicana" —una epojé de casi 20 años por hablar solo de sus efectos visibles-, la transición a la democracia sería una "suspensión": la ciudadanía permanecía ausente mientras tanto la situación se normalizaba, si la metáfora se interpreta temporalmente; el país estuvo suspendido, colgando del metaestable equilibrio aportado por el consenso sonoro de los que tienen parte, si se interpreta espacialmente.

Sin embargo, lo que llegaría a ser normal fue justamente la transición misma sin que se echara en falta, de menos, nada más porque la transición nos acostumbró a la falta, al duelo. A hablar bajito para que no se oyera el lenguaje detrás del ruido molesto, el sentido por sobre el rumor: Chile se encontraba sumergido en aguas turbias y de esas aguas no lograría salir inmaculado.

Esta suspensión semeja la situación del derecho a la educación y la circunstancia por la que ha atravesado la responsabilidad del Estado respecto de ella. En cuanto derecho, en efecto, la educación ha estado también suspendida, supeditada a las condiciones límite de un tipo de consenso social cuyos alcances manifiestos relegarían la protesta y el disenso al silencio, el compromiso del Estado era en la medida de lo posible.

Pero dejar en el silencio, sin voz, a los que no tienen parte, no es otra cosa que la repetición neurótica del gesto arquetípico de la transición: un gesto que apela a la "acción concreta" como manifestación del rechazo a la ideología, que considera a esta "no más que palabras" a las que debe responderse con realizaciones efectivas.

En esas circunstancias resuena la doble pregunta de Lyotard, pero como mero ruido. Sería la falta de palabras, es decir, la ausencia de un sentido que transmitir lo que conduciría a los sin parte a tomar la palabra y anunciar en las calles la necesidad de revisar el rol del

$11 \quad$ Insigne político chileno de actuación prevaleciente en la primera mitad del siglo XIX, además de haberse dedicado a los negocios. Se le reconoce como el gran organizador del Estado nacional. 
Estado, a denunciar el lucro y la segregación y, en fin, a cuestionar la legitimidad del sistema educacional y, a través suyo, la legitimidad del sistema político y social chileno en su conjunto.

En este complejo escenario estaba la política educativa cuando advino el gobierno de derecha, cuya propuesta educativa, más allá de los criterios señalados, se inscribe en la profundización de la privatización del sistema de educación pública, consistente con su proyecto ideológico, hacer que no se oculte tras medidas distractivas, sino que esté en la superficie de su actuar. La privatización abierta, ya ocurrida en los años de la dictadura y primera década de la democracia, dio espacio a formas más elaboradas de privatización encubierta, no basadas en la construcción de empresas bajo regímenes legales complejos, sino en preponderancia de los argumentos de la libertad de enseñanza y del derecho de las personas a la elección, que si bien no son nuevos, aún reportan importantes réditos, pues la construcción del Estado democrático chileno en educación se ha hecho desde ese paradigma ideológico, y no desde el de los derechos sociales, por ende, no es necesario su encubrimiento, opera sin tapujos a sabiendas que la disputa ideológica en esta materia pareciera — desde su argumentación — estar lograda.

\section{REFERENCIAS BIBLIOGRÁFICAS}

Alarcón, J., Castro, M., Gajardo, C., \& Frites C. (2016). Desafíos de la educación preescolar en Chile: Ampliar la cobertura, mejorar la calidad y evitar el acoplamiento. Estudios Pedagógicos, XLI(2), 287-303.

Atria, F. (2014). Derechos sociales y educación: un nuevo paradigma de lo político. Santiago de Chile: LOM Ediciones.

Ball, S., \& Youdell, D. (2007). Privatización Encubierta de la Educación Pública (Informe). Londres: Instituto de Educación, Universidad de Londres.

Bellei, C. (2015). El gran experimento. Mercado y privatización de la educación chilena. Santiago de Chile: LOM Ediciones.

Bellow, S. (1964). Herzog. Nueva York: Vikings Press.

Donoso, S. (2013). El Derecho a Educación en Chile, Nueva ciudadanía tras el ocaso neoliberal. Santiago de Chile: Bravo y Allende Editores.

Donoso, S., \& Alarcón, J. (2015). ¿Nuevo Paradigma en la Política Educativa Chilena? Debates sobre educación y transformación social (Doc. de Trabajo). Talca: Instituto de investigación y Desarrollo Educacional, Universidad de Talca.

Donoso, S., Castro, M., \& Alarcón, J. (2015). Aspectos críticos en las propuestas sobre una nueva arquitectura de la educación pública chilena. Estudios Pedagógicos, XLI(2), 305-324.

Harvey, D. (2007). Breve historia del neoliberalismo. Madrid: Akal.

Honorable Congreso Nacional. (2009). Ley General de Educación. Santiago de Chile. Ministerio de Educación.

Instituto Libertad y Desarrollo. (2014). Temas Públicos, 149. Santiago de Chile: Autor.

Junta de Gobierno. (1990). Constitución Política de la República de Chile. Santiago de Chile: Editorial Andrés Bello.

Kingdom, J. (1995). Agendas, Alternatives and Public Policies. New York: Logman.

Krugman, P. (2009). The Returns of Depression Ecomics and the crisis of 2008. New York: W. W. Norton Company.

Lakoff, G. (2004). Don't Think of an Elephant!: Know Your Values and Freme the Debate. Chelsea. Vermont: Green publishing. 
Lyotard, J. F. (1989). La condición postmoderna. Madrid: Cátedra.

Ministerio de Educación. (2011). Políticas y propuestas de acción para el desarrollo de la educación chilena. Santiago de Chile: Autor.

Osborne, D., \& Gaebler, T. (1993). Reinventing Government: How the Entrepreneurial Spirit is Transforming the Public Sector. Plume: Massachusetts.

Rodríguez, M. (2005). La transformación del Estado chileno: El caso de la Reforma Educacional de los 90. Berlin, August: Forschungs und Dokumentationszentrum Chile-Lateinamerika e.V. (FDCL).

Sennet, R. (2007). La cultura del nuevo capitalismo. Barcelona: Anagrama.

Tomasevski, K. (2004). El Asalto a la Educación. Barcelona: Editorial Intermón-OXFAM.

Whitty, G. (2000). Privatisation and marketisation in education policy. Paper delivered at an NUT conference on 'Involving the Private Sector in Education: Value Added or High Risk?', London, 21 November 2000.

Zizek, S. (2008). En defensa de la intolerancia. Madrid: Sequitur. 